\title{
CALÇADAS COM DIFERENTES TIPOS E VARIAÇÕES DE PISOS Uma avaliação estética por grupos com distintas formações educacionais
}

\author{
Sidewalks with different types and variations of paving \\ An aesthetic evaluation by groups with different educational backgrounds
}

\begin{abstract}
Knapp, Chrystiane;
(Faculdade de Arquitetura - PROPUR, Universidade Federal do Rio Grande do Sul) chrys.knapp@gmail.com Reis, Antônio Tarcísio da Luz;

(Faculdade de Arquitetura - PROPUR, Universidade Federal do Rio Grande do Sul) tarcisio@orion.ufrgs.br
\end{abstract}

\section{RESUMO}

Este artigo analisa as preferências de pisos e o impacto estético das variações dos pisos de calçadas ao longo da mesma quadra, na percepção de três grupos de respondentes com distintas formações educacionais. Foram apresentadas para a análise de impacto estético doze vistas de pisos mais recorrentes e três percursos de calçadas com diferentes níveis de variações de pisos ao longo da mesma quadra, conforme segue: (i) alta heterogeneidade: grande variedade de pisos; (ii) média heterogeneidade: média variedade de pisos, e (iii) homogeneidade, sem variação de pisos. Os dados foram coletados através de questionários on-line para moradores de Porto Alegre e RMPA, categorizados em: (38) arquitetos; (69) não arquitetos com formação universitária e (10) respondentes sem formação universitária, e analisados através de testes estatísticos não paramétricos. Os principais resultados evidenciam maior preferência por pisos de tamanhos e cores uniformes, assim como impacto positivo por percursos de calçada com pisos homogêneos.

Palavras chaves: calçada, estética, piso de calçada, percepção do usuário.

Bloco temático: espacio público y proyecto urbano en la metrópolis contemporánea.

\begin{abstract}
This article analyzes the preferences of sidewalk surface and the aesthetic impact of the variations of the paving along the same block, in the perception of three groups of respondents with different educational backgrounds. Twelve more recurrent sidewalk surface views and three sidewalk paths with different levels of paving variation along the same block were presented for the aesthetic impact analysis, as follows: (i) high heterogeneity: wide variety of paving; (ii) average heterogeneity: medium variety of paving, and (iii) homogeneity, without variation of paving. Data were collected through online questionnaires for residents of Porto Alegre and RMPA, categorized in: (38) architects; (69) non-architects with university education and (10) respondents without university education, and analyzed through non-parametric statistical tests. The main results show a greater preference for uniform size and color of sidewalk surface, as well as positive impact on sidewalk paths with homogeneous paving.
\end{abstract}

Keywords: sidewalk, aesthetic, sidewalk surface, user perception.

Topic: public space and urban project in the contemporary metropolis. 


\section{Introdução}

Em cidades, tais como, Melbourne (Melbourne City Council, 2013), Washington (Government of the District of Columbia, 2011) e Londres (Transport for London, 2017) existe uma padronização dos pisos das calçadas, onde a responsabilidade da execução é em grande parte do município. Contudo, em várias cidades brasileiras, incluindo Porto Alegre e outras capitais de estados, o planejamento, a execução e a manutenção das calçadas são de responsabilidade do proprietário de cada lote lindeiro (Lei $N^{\circ} 1.350,1988$; Decreto $N^{\circ} 17.302,2011$; Lei Complementar $\left.\mathrm{N}^{\circ} 482,2014\right)$, frequentemente, gerando uma grande variedade de pisos em uma mesma quadra. A variedade de revestimentos que atendam as normas não é inconveniente, mas sim, a dissociação destes com relação as suas adjacências. Ainda, algumas cidades instruem que a pavimentação da calçada harmonize com o entorno existente, porém, não fica claro de que maneira esta harmonização deve acontecer, como por exemplo, seguindo as cores ou desenho existentes, ou utilizando o mesmo material de piso contíguo, para citar alguns exemplos de instruções (Lei №3.144, 2005; Decreto № 45.904, 2005).

O guia de calçadas da World Resources Institute (WRI Brasil, 2017) lembra que a pavimentação das calçadas pode ser projetada para melhorar a qualidade estética do ambiente, contudo, é inconsistente de que maneira isso pode ser logrado. Nesse sentido, a cartilha de Londres (Transport for London, 2017) enfatiza que o piso de suas calçadas deve responder às diferentes características do entorno como um "carpete" neutro, complementando as edificações adjacentes, ao em vez de se destacar, e recomenda os tipos de revestimentos que podem ser utilizados, além de indicar onde e como devem ser instalados. Todavia, trabalhos sobre o aspecto da paisagem urbana revelam que a aparência agradável do entorno urbano pode incentivar a caminhada das pessoas (Van Cauwenberg et al., 2012). Além disso, assim como outros elementos urbanos contínuos, o tipo de pavimentação contínua em um bairro, tal como no calçadão de Copacabana (Fig. 1) e de Ipanema (Fig. 2) no Rio de Janeiro pode gerar uma percepção de região unificada e de unidade temática facilmente identificável (Lynch, 2008). Ainda assim, muitas cidades brasileiras não consideram a calçada como um elemento importante na composição e na estética do espaço urbano, isso se reflete ao derivar a responsabilidade da construção da calçada a cada proprietário de lote, além de não esclarecer fatores de padronização e harmonização, resultando no "pot-pourri" de calçadas desassociadas que hoje fazem parte do contexto urbano brasileiro. No entanto, o piso da calçada possui uma relação direta com os usuários dos espaços abertos públicos, logo, a escolha adequada torna-se relevante na idealização de ambientes urbanos esteticamente positivos, assim como, na experiência agradável e no incentivo à caminhada.

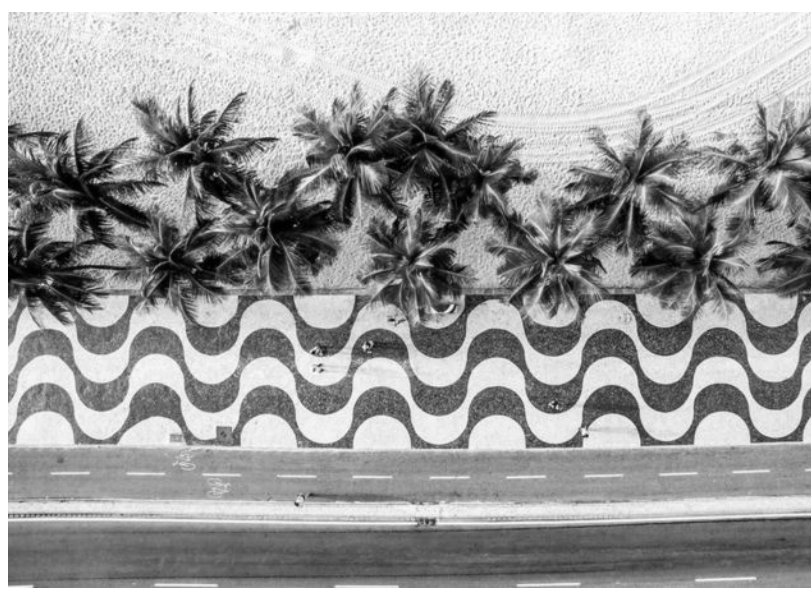

Fig. 1. Calçadão de Copacabana - Rio de Janeiro Fonte: https://www.bbc.com/portuguese/geral-38503322

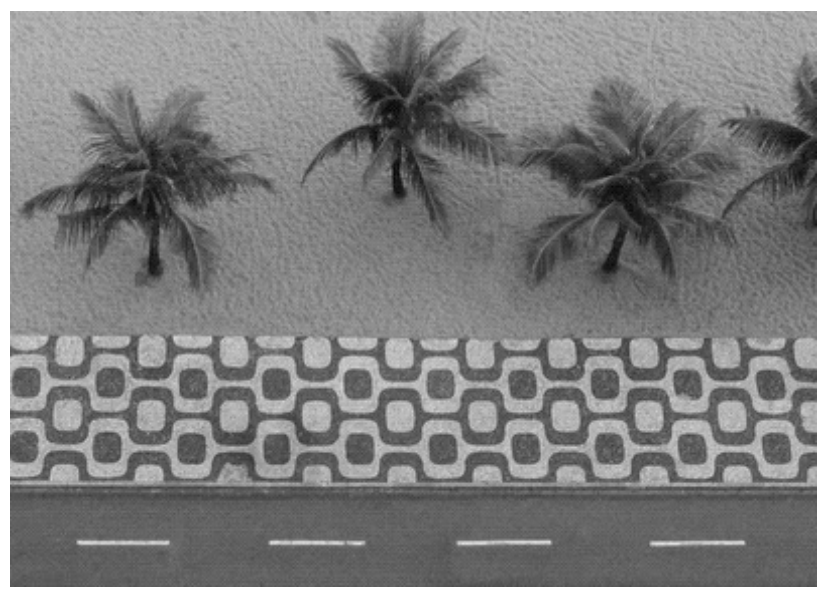

Fig. 2. Calçadão de Ipanema - Rio de Janeiro Fonte:http://blogandancas.blogspot.com/2011/05/calcadas.html

Dessa forma, existe uma carência de estudos, principalmente no caso das calçadas de cidades brasileiras, que avaliem a preferência com relação ao tipo de piso utilizado, assim como o impacto estético provocado pela grande variação de pisos com relação a cores, texturas, formato, tamanho e sua disposição ao longo de uma 
mesma quadra, levando em consideração a satisfação de diferentes grupos de respondentes. A análise estética torna-se importante, dado que não basta apenas ter uma calçada que atenda aos requisitos das normas técnicas e legislações, a aparência é importante tanto quanto a sua funcionalidade, pois conforme normas (ABNT NBR 9050, 2015; ABNT NBR 1338, 1990) e legislações municipais (Decreto $N^{\circ} 45.904,2005$; Decreto $N^{\circ} 17.302,2011$ ) é o proprietário quem determina o melhor revestimento a ser implantando na frente do seu lote, resultando em escolhas conforme a sua agradabilidade ou conveniência, inclusive muitas vezes desconsiderando aspectos de uniformidade e harmonia com o entorno. Assim, este artigo apresenta uma avaliação estética com relação ao piso da calçada, por diferentes grupos de respondentes e pretende comprovar as seguintes hipóteses: (a) quanto mais neutro e com menos detalhes for o piso, maior o impacto estético positivo; (b) quanto maior a variação dos pisos das calçadas ao longo de uma mesma quadra, com relação a cores, texturas, formato, tamanho e disposição, maior o impacto estético negativo. É também examinada a existência de diferenças ou não entre as respostas estéticas de grupos de respondentes com distintos níveis e tipos de formação educacional, nomeadamente, arquitetos, não arquitetos com formação universitária e respondentes sem formação universitária.

\section{Metodologia}

Para responder às hipóteses acima explicitadas, foram coletados dados através de questionários disponibilizados no programa LimeSurvey, via internet, e aplicados a 38 arquitetos, 69 não arquitetos com formação universitária e 10 respondentes sem formação universitária. Como critério de participação, o respondente deveria residir em Porto Alegre ou Região Metropolitana de Porto Alegre e ser maior de 18 anos. Ainda, os respondentes da categoria de não arquitetos com formação universitária não poderiam ser graduados em cursos cujos conteúdos tratassem de estética, tais como áreas relacionadas à arte, design e publicidade e propaganda, de maneira a caracterizar uma amostra sem formação estética, ao contrário da amostra de arquitetos. O link (caminho) de acesso ao questionário foi divulgado através da rede social Facebook, a partir da conta pessoal do primeiro autor e via e-mail, solicitando aos respondentes o reenvio do link para os seus contatos, utilizando-se da técnica de amostra em bola de neve (snowball sample) (Handcock e Gile, 2011), a fim de aumentar o número da amostra.

O questionário foi constituído por questões simples e de múltipla escolha, e dividido em duas avaliações. Para a avaliação da preferência estética de pisos de calçadas, foram incluídas no questionário doze vistas que representassem os tipos de pisos mais recorrentes nas calçadas de Porto Alegre (Fig. 3 até a Fig. 14). Destas doze vistas os respondentes selecionaram as três vistas mais preferidas quanto à aparência dos pisos, logo, as três vistas menos preferidas e justificaram as suas escolhas. Para avaliação da aparência dos diferentes níveis de variação de pisos ao longo de uma mesma quadra, foram incluídos no questionário três links que direcionavam a uma plataforma de compartilhamento de vídeos (YouTube), onde os vídeos representavam percursos de calçadas com diferentes níveis de variação de pisos, ao longo de uma mesma quadra, especificamente: (i) alta heterogeneidade, representada pela maior variação possível de pisos (Fig. 15); (ii) média heterogeneidade, representada pela variação de um mesmo tipo de piso (pedra basalto), porém com diferentes tamanhos e disposições (Fig. 16) e (iii) homogeneidade, representada por um único tipo de piso (Fig. 17). Cada percurso foi avaliado individualmente quanto à aparência da calçada, com perguntas do tipo: "Você acha a aparência da calçada do percurso 1: (muito satisfatória; satisfatória; nem satisfatória, nem insatisfatória; insatisfatória; muito insatisfatória)" ademais, foi solicitado ao respondente que ordenasse os percursos do mais para o menos preferido, com perguntas como: "Ordene os percursos, do mais (1) para o menos (3) preferido quanto à aparência das calçadas: (Percurso 1 [ ]; Percurso 2 [ ]; Percurso 3 [ ])", com as respectivas justificativas de suas escolhas. Um estudo piloto foi aplicado com seis respondentes, arquitetos, de maneira a verificar a compreensão e clareza das questões, das imagens e dos vídeos apresentados. As respostas do questionário foram transferidas para o programa estatístico SPSS/PC (Social Package for Social Sciences) e 
analisados através de testes estatísticos não paramétricos, como frequências, tabulação cruzada (Phi), Kruskal-Wallis e Kendall W. Os testes são considerados estatisticamente significativos quando o valor de significância é igual ou inferior a 0,05 (sig. $\leq 0,05$ ) (Lay e Reis, 2005).

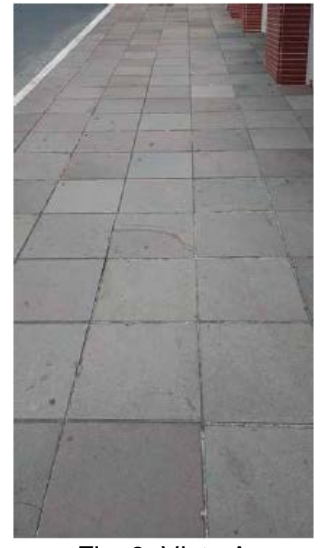

Fig. 3. Vista A

Basalto regular

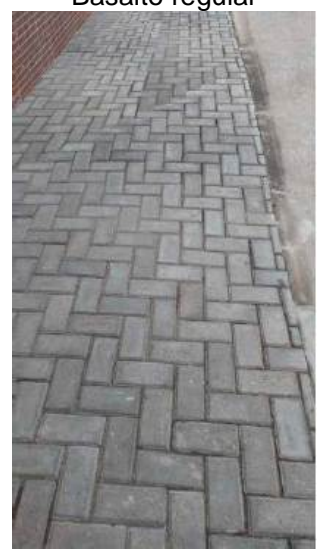

Fig. 7. Vista $\mathrm{E}$

Concreto intertravado

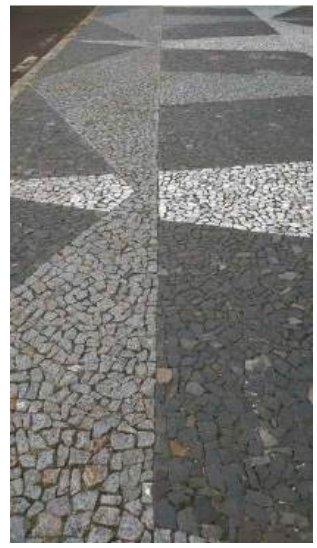

Fig. 11. Vista I

Pedra portuguesa, desenho geométrico

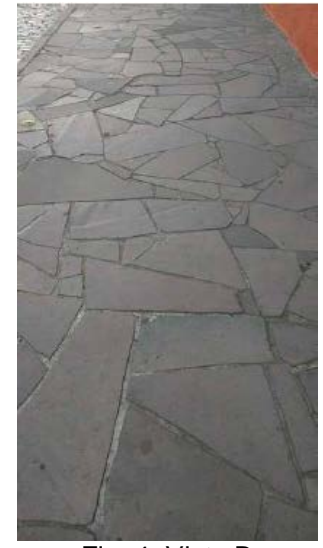

Fig. 4. Vista B

Basalto irregular

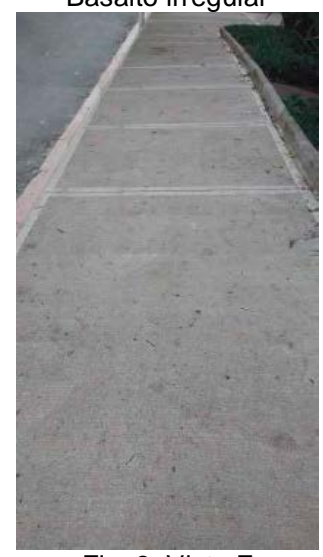

Fig. 8. Vista F

Concreto moldado in-loco

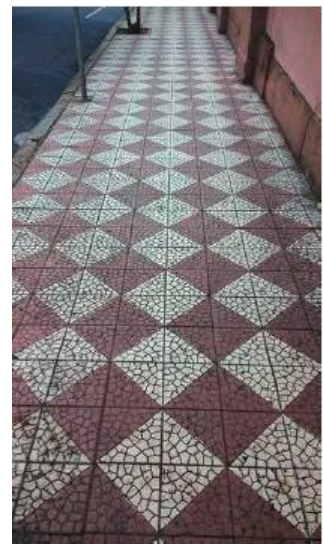

Fig. 12. Vista J

Ladrilho hidráulico, losango vermelho e branco

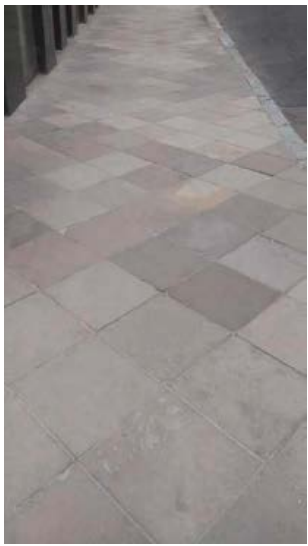

Fig. 5. Vista $C$

Basalto regular a $45^{\circ}$

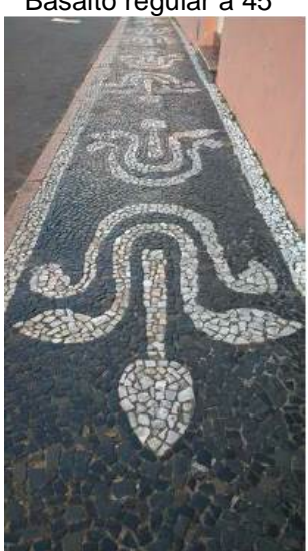

Fig. 9. Vista $G$ Pedra portuguesa desenho arabesco

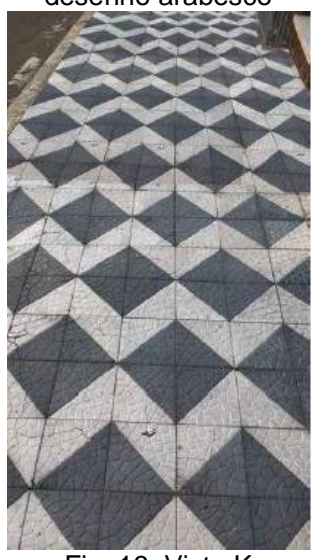

Fig. 13. Vista K Ladrilho hidráulico, losango azul e branco

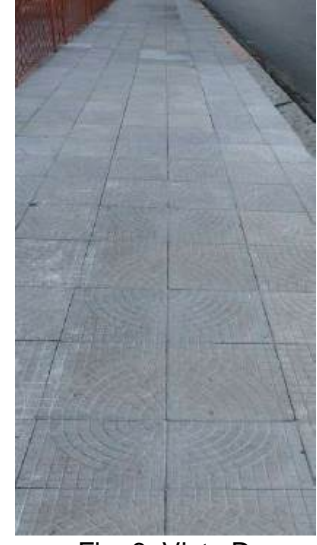

Fig. 6. Vista D

Placa de concreto estampada

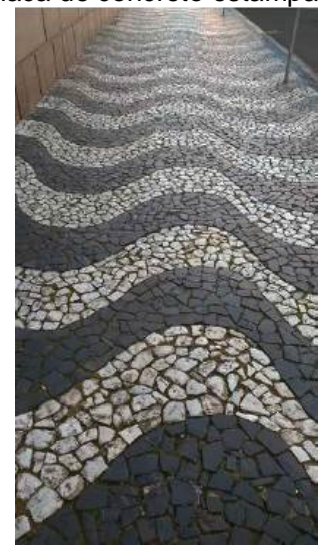

Fig. 10. Vista $\mathrm{H}$

Pedra portuguesa desenho ondas

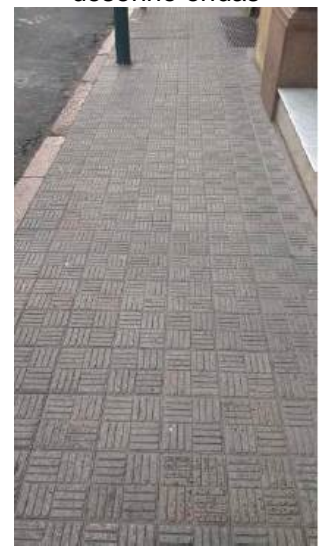

Fig. 14. Vista L

Ladrilho hidráulico, cinza

Fonte: Knapp, 2018 


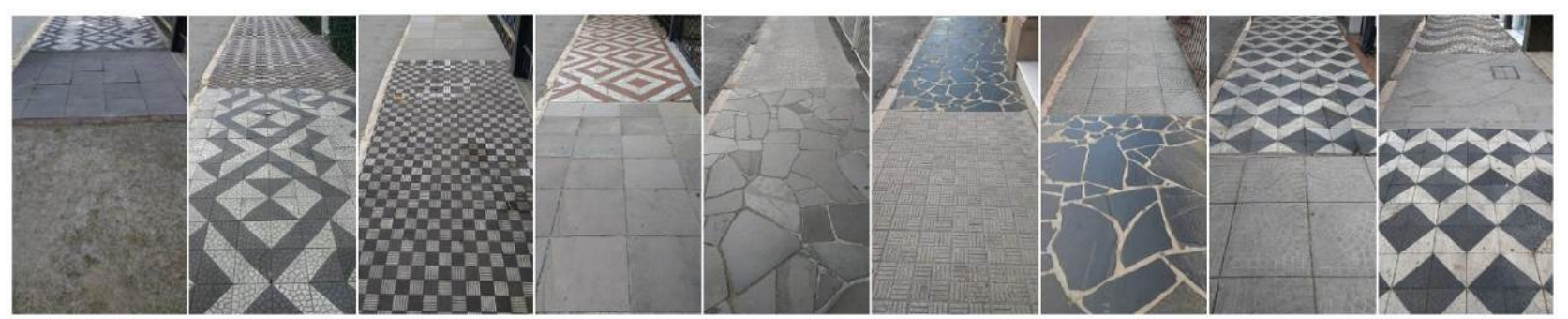

Fig. 15. Percurso 1 - Piso alta heterogeneidade - maior variedade de pisos possíveis ao longo de uma mesma quadra (cenas dispostas na ordem em que apareceram no vídeo). Fonte: Knapp, 2018

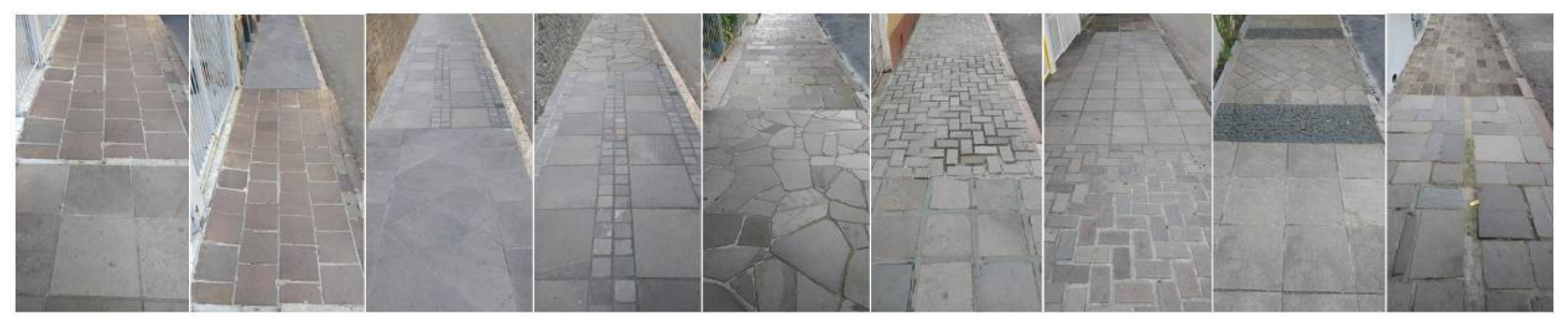

Fig. 16. Percurso 2 - Piso média heterogeneidade - variação de um mesmo tipo de piso (pedra basalto), porém com diferentes tamanhos e disposições, ao longo de uma mesma quadra (cenas dispostas na ordem em que apareceram no vídeo). Fonte: Knapp, 2018

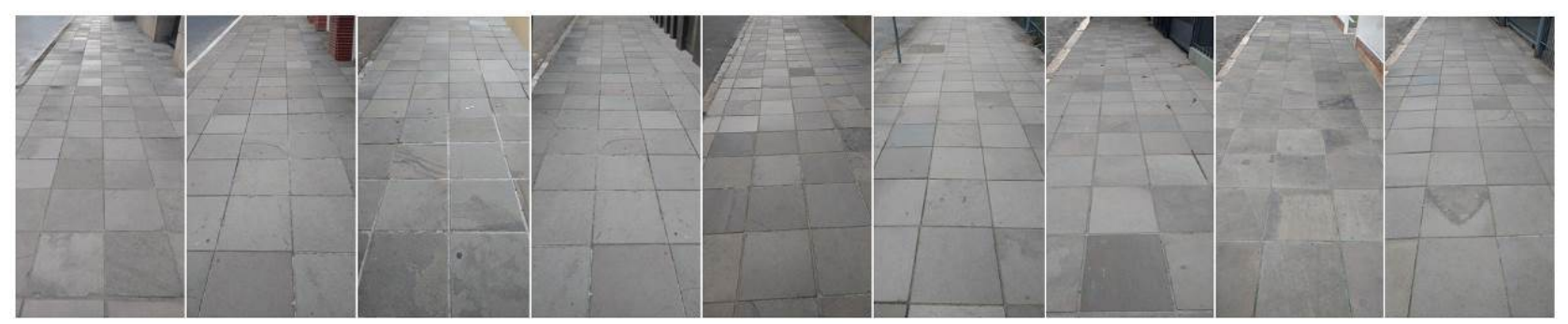

Fig. 17. Percurso 3 - Piso homogêneo - único tipo de piso ao longo de uma mesma quadra (cenas dispostas na ordem em que apareceram no vídeo). Fonte: Knapp, 2018

\section{Resultados}

\subsection{Preferência pelos pisos de calçadas}

As vistas $A, C$ e $L$ são as três mais preferidas pelos arquitetos dentre as 12 vistas, respectivamente, selecionadas por $42,1 \%, 36,8 \%$ e $34,2 \%$ destes respondentes (Fig. 18). As principais razões para justificar estas preferências pelos pisos das calçadas foram o desenho $(63,2 \%)$, o tamanho regular $(60,5 \%)$, o tipo de material (60,5\%), a cor neutra (50\%), a cor uniforme (44,7\%), e a textura dos pisos (42,1\%) (Tabela 1). As vistas, G, B e J são as três menos preferidas, respectivamente, indicadas por $52,6 \%, 42,1 \%$ e $36,8 \%$ dos arquitetos (Fig. 19). Tais escolhas foram justificadas pelo desenho (65,8\%), a textura (44,7\%), o tipo de material $(44,7 \%)$, a variedade de cores $(36,8 \%)$ e de tamanhos dos pisos $(34,2 \%)$ (Tabela 1$)$.

Para o grupo de não arquitetos com formação universitária as vistas C (46.4\%), A (40.6\%), D (31,9\%) e G $(31,9 \%)$ são as mais preferidas dentre as 12 vistas (Fig. 18). As principais razões para justificar estas escolhas pelos pisos das calçadas foram a cor uniforme (53,6\%), o desenho do piso $(50,7 \%)$, o material do piso $(49,3 \%)$ e o mesmo tamanho de pisos (40,36\%) (Tabela 1 ). As vistas I, J e F são as três vistas menos preferidas respectivamente, indicadas por $50,7 \%, 44,9 \%$ e $34,8 \%$ dos não arquitetos (Fig. 19). As principais razões para justificar estas menores preferências pelos pisos da calçada foram o desenho (60,9\%), a textura (49,3\%) e o material do piso $(47,8 \%)$ (Tabela 1$)$. Embora a vista $G$ esteja entre as vistas mais preferidas, uma expressiva parte dos não arquitetos escolheu-a também como não preferida $(33,3 \%)$. 


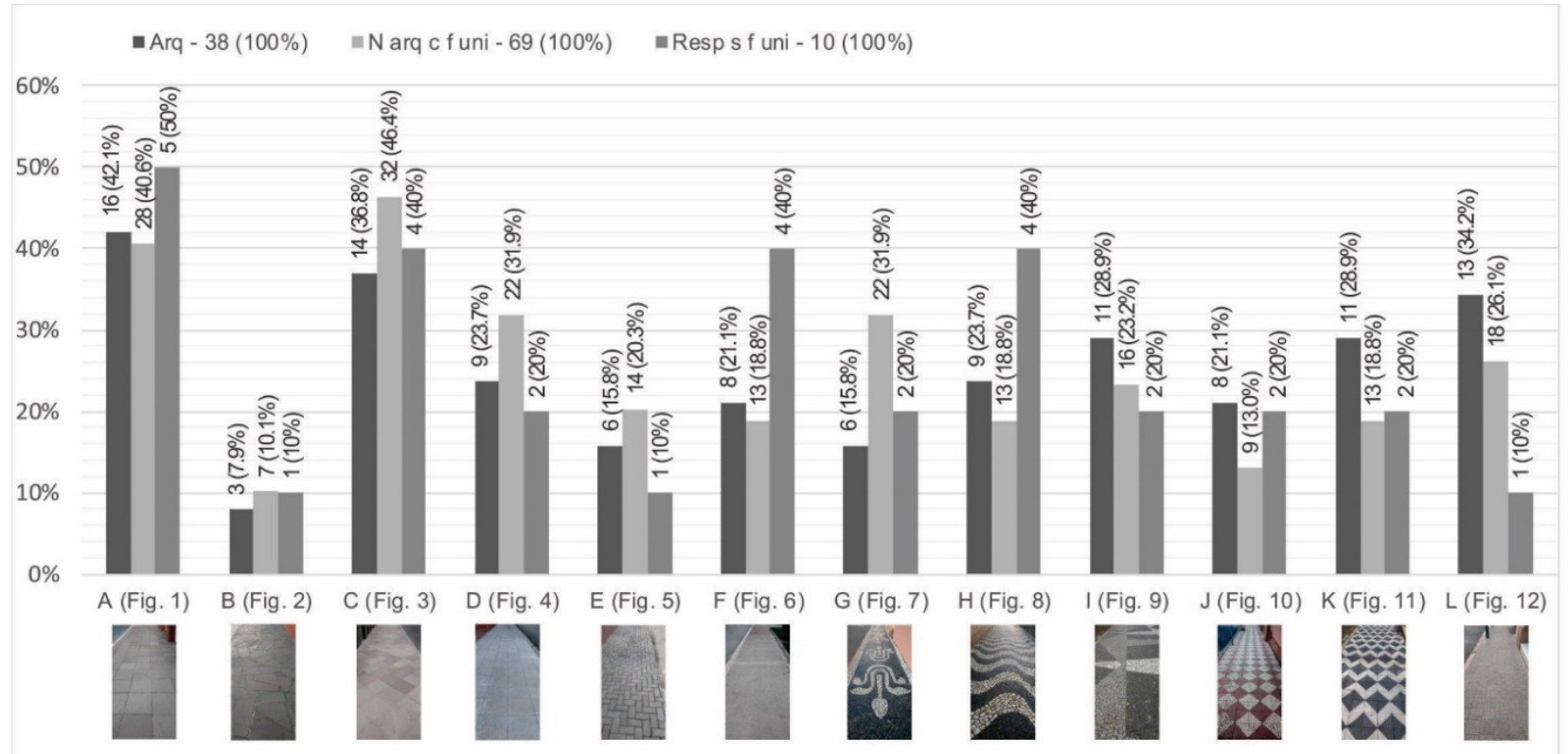

Fig. 18.Vistas de pisos de calçadas mais preferidas. Fonte: Elaboração própria, a partir dos dados coletados.

Para os respondentes sem formação universitária as vistas A (50\%), C (40\%), F (40\%) e H (40\%) são as mais preferidas dentre as 12 vistas (Fig. 18). As principais razões para justificar as vistas dos pisos mais preferidos foram os mesmos tamanhos de pisos (70\%), a textura (50\%), o desenho (40\%), o material (40\%), a cor uniforme (40\%), a presença de cores (40\%) e a variedade de cores dos pisos (40\%) (Tabela 1). As vistas D, J e I são as três vistas menos preferidas, respectivamente, indicadas por $60 \%, 50 \%$ e $40 \%$ dos respondentes (Fig. 19). A principal razão para justificar estas menores preferências pelos pisos da calçada foi a textura dos pisos (40\%) (Tabela 1). Ainda que a vista $F$ tenha sido escolhida como mais preferidas, uma parte importante dos respondentes sem formação universitária escolheu-a como não preferida (30\%) (Fig. 19).

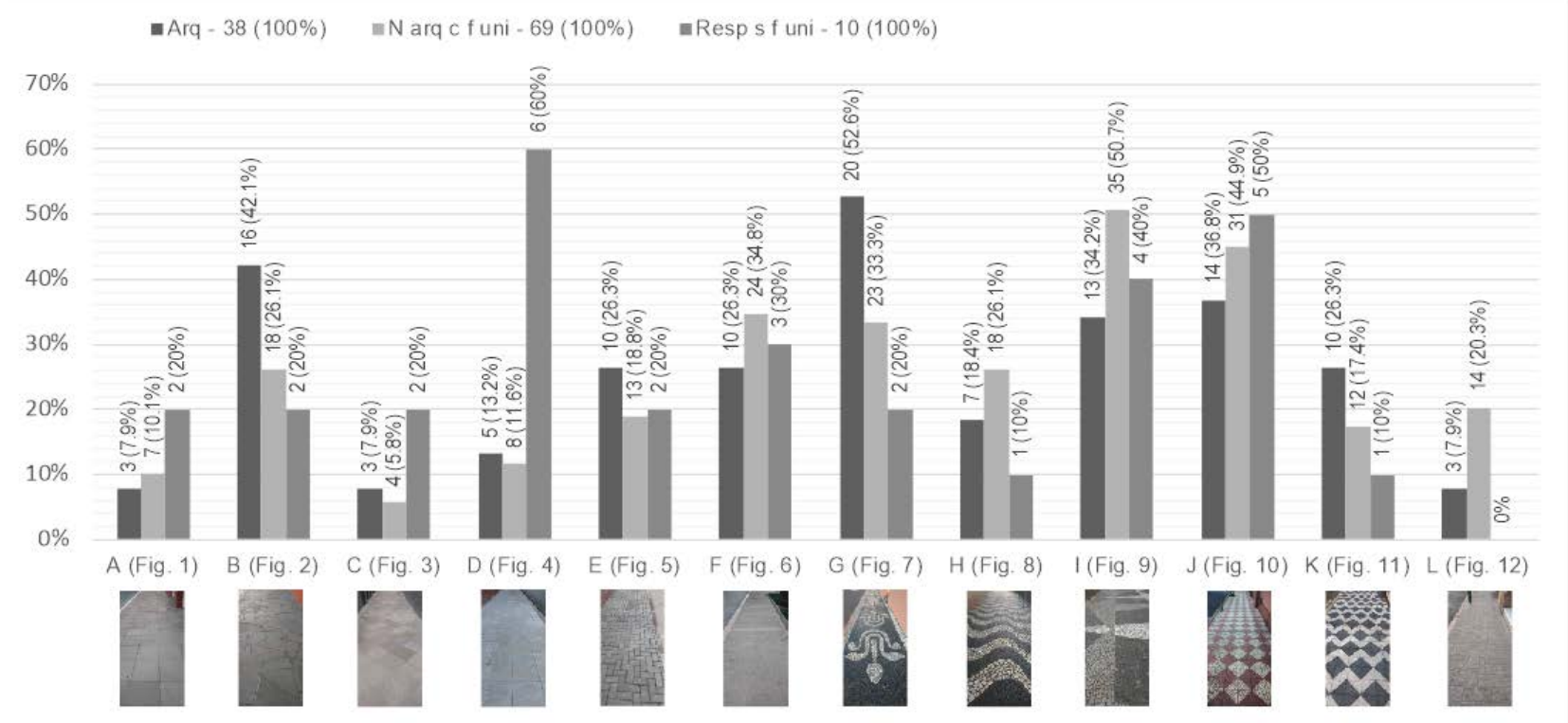

Fig. 19. Vistas de pisos de calçadas menos preferidas. Fonte: Elaboração própria, a partir dos dados coletados.

Observa-se que os três grupos de respondentes indicam as vistas A (Fig. 3) e C (Fig. 5), ambas representadas pela pedra basalto de tamanho e recorte regular, entre suas escolhas pelas vistas mais preferidas (Fig. 18). Portanto, pisos de recortes e tamanhos regulares, de cor homogênea e colocados ordenadamente tendem a 
ser avaliados de maneira positiva por cada um dos três grupos. Isso fica ainda mais evidenciado nas avalições dos arquitetos, onde a escolha por pisos mais sóbrios e homogêneos se destacam (vistas A, C e L). Ainda, entre as vistas mais preferidas para os grupos de não arquitetos com formação universitária e aqueles sem formação universitária, aparecem vistas compostas com pedra portuguesa (vistas $\mathrm{G} \mathrm{e} \mathrm{H}$, respectivamente), o que pode significar que para estes dois grupos a presença de algum estímulo no piso, como cor ou desenho, são vistos como fatores positivos. Com relação às vistas menos preferidas, aquelas representando a pedra portuguesa com desenhos geométricos (vista I, Fig. 11) e ladrilho hidráulico nas cores vermelho e branco (vista J, Fig. 12) foram indicadas como as menos preferidas pelos três grupos de respondentes. Portanto, os três grupos tendem a rejeitar, em maior número, pisos com desenhos e tamanhos irregulares, somados às cores mais chamativas. Contudo, os respondentes sem formação universitária, rejeitam pisos que remetem a regularidade, como as vistas D e F, que também foram julgadas como as menos preferidas por esses (Fig. 19).

\begin{tabular}{|c|c|c|c|c|c|c|}
\hline Justificativas & $\begin{array}{c}\text { Arquitetos } \\
38(100 \%)\end{array}$ & $\begin{array}{c}\text { N arq c f uni } \\
69(100 \%)\end{array}$ & $\begin{array}{c}\text { Resp s f uni } \\
10(100 \%)\end{array}$ & $\begin{array}{c}\text { Total } \\
117(100 \%)\end{array}$ & SIG & PHI \\
\hline \multicolumn{7}{|c|}{ JUSTIFICATIVAS PARA AS TRÊS VISTAS MAIS PREFERIDAS } \\
\hline Desenho do piso & $24(63,2 \%)$ & $35(50,7 \%)$ & $4(40 \%)$ & $63(53,8 \%)$ & 0,306 & 0,142 \\
\hline Material do piso & $23(60,5 \%)$ & $34(49,3 \%)$ & $4(40 \%)$ & $61(52,1 \%)$ & 0,389 & 0,127 \\
\hline Mesmos tamanhos de pisos & $23(60,5 \%)$ & $28(40,6 \%)$ & $7(70 \%)$ & $58(49,6 \%)$ & 0,057 & 0,221 \\
\hline Cor uniforme & $17(44,7 \%)$ & $37(53,6 \%)$ & $4(40 \%)$ & $58(49,6 \%)$ & 0,556 & 0,100 \\
\hline Cor neutra & $19(50,0 \%)$ & $26(37,7 \%)$ & $3(30 \%)$ & $48(41,0 \%)$ & 0,352 & 0,134 \\
\hline Textura do piso & $16(42,1 \%)$ & $24(34,8 \%)$ & $5(50 \%)$ & $45(38,5 \%)$ & 0,557 & 0,100 \\
\hline Presença de cores & $6(15,8 \%)$ & $12(17,4 \%)$ & $4(40 \%)$ & $22(18,8 \%)$ & 0,196 & 0,167 \\
\hline Variedade de cores & $4(10,5 \%)$ & $12(17,4 \%)$ & $4(40 \%)$ & $20(17,1 \%)$ & 0,088 & 0,204 \\
\hline \multicolumn{7}{|c|}{ JUSTIFICATIVAS PARA AS TRÊS VISTAS MENOS PREFERIDAS } \\
\hline Desenho do piso & $25(65,8 \%)$ & $42(60,9 \%)$ & $2(20 \%)$ & $69(59,0 \%)$ & 0,029 & 0,247 \\
\hline Textura do piso & $17(44,7 \%)$ & $34(49,3 \%)$ & $4(40 \%)$ & $55(47,0 \%)$ & 0,811 & 0,060 \\
\hline Material do piso & $17(44,7 \%)$ & $33(47,8 \%)$ & $3(30 \%)$ & $53(45,3 \%)$ & 0,569 & 0,098 \\
\hline Variedade de cores & $14(36,8 \%)$ & $26(37,7 \%)$ & $2(20 \%)$ & $42(35,9 \%)$ & 0,547 & 0,102 \\
\hline Vários tamanhos de pisos & $13(34,2 \%)$ & $24(34,8 \%)$ & $3(30 \%)$ & $40(34,2 \%)$ & 0,957 & 0,028 \\
\hline Presença de cores & $9(23,7 \%)$ & $16(23,2 \%)$ & $3(30 \%)$ & $28(23,9 \%)$ & 0,894 & 0,044 \\
\hline Cor neutra & $1(2,6 \%)$ & $8(11,6 \%)$ & $2(20 \%)$ & $11(9,4 \%)$ & 0,153 & 0,179 \\
\hline Cor uniforme & $2(5,3 \%)$ & $5(7,2 \%)$ & $3(30 \%)$ & $10(8,5 \%)$ & 0,038 & 0,237 \\
\hline
\end{tabular}

Tabela 1. Justificativas relacionadas à preferência de pisos (Vistas A-B-C-D-E-F-G-H-I-J-K-L).

Notas: são apresentadas as justificativas mais mencionadas, pelo menos, por $20 \%$ dos respondentes de cada grupo; $N$ arq c $f$ uni $=$ não arquiteto com formação universitária; Resp s $f$ uni = respondente sem formação universitária; os valores de sig e phi foram obtidos através de tabulação cruzada.

\subsection{Avaliação da aparência dos diferentes níveis de variação de pisos ao longo de uma mesma quadra}

Através do teste estatístico Kendall W, são identificadas diferenças entre as avaliações das aparências dos três percursos com diferentes níveis de variação de pisos pelos respondentes de cada grupo (arquitetos, não arquitetos com formação universitária e respondentes sem formação universitária). Uma diferença estatisticamente significativa foi encontrada entre as avaliações das aparências dos percursos pela amostra de arquitetos (Kendall $W, X^{2}=39,984$, sig $=0,000$ ), não arquitetos com formação universitária (Kendall $W$, $X^{2}=61,851$, sig=0,000) e pelos respondentes sem formação universitária (Kendall $W, X^{2}=8,273$, sig=0,016). Essas diferenças evidenciam que percursos com pisos de calçadas com distintos níveis de heterogeneidade são avaliados diferentemente.

O percurso mais bem avaliado pelos arquitetos foi o percurso 3 ( $73,7 \%$ de avaliações positivas - Fig. 17). $O$ percurso mais mal avaliado pelos arquitetos foi o percurso 1 (55,3\% de avaliações negativas - Fig. 15) (Tabela 2). O percurso mais bem avaliado pela expressiva maioria dos não arquitetos com formação universitária 
também foi o percurso 3 (84\%), enquanto o percurso mais mal avaliado por este grupo foi o percurso $1(37,7 \%)$ (Tabela 2). O percurso mais bem avaliado pelos respondentes sem formação universitária, novamente, foi o 3 (70\%), sendo este o único percurso a não ser avaliado negativamente por este grupo, enquanto o percurso 2 foi o mais mal avaliado (30\%) (Tabela 2).

Dessa forma, o percurso 3 (Fig. 17 - percurso homogêneo) foi avaliado como o percurso mais satisfatório por cada um dos três grupos de respondentes (Tabela 2), evidenciando o impacto positivo de pisos uniformes ao longo de uma mesma quadra, que remetem à ideia de ordem e regularidade dos pisos das calçadas. Ademais, foi o único percurso, dentre os três, avaliado positivamente (muito satisfatório ou satisfatório) por mais de 70\% do total de cada amostra, e com a menor proporção de respondentes insatisfeitos (Tabela 2).

Por outro lado, o percurso 1 (Fig. 15 - percurso com alta heterogeneidade) foi o mais mal avaliado pelos arquitetos e não arquitetos com formação universitária, sendo expressivamente pior avaliado pelos arquitetos (Tabela 2), enquanto o percurso 2 (Fig. 16 - percurso com média heterogeneidade) foi o pior avaliado por aqueles sem formação universitária. Logo, as calçadas com variação de pisos, ao longo de uma mesma quadra, tendem a provocar reações estéticas negativas por parte dos três grupos de respondentes.

\begin{tabular}{|c|c|c|c|}
\hline $\begin{array}{c}\text { Níveis } \\
\text { de Satisfação }\end{array}$ & $\begin{array}{l}\text { Percurso } 1 \text { - Fig. } 16 \\
\text { (alta heterogeneidade) }\end{array}$ & $\begin{array}{c}\text { Percurso } 2 \text { - Fig. } 17 \\
\text { (média heterogeneidade) }\end{array}$ & $\begin{array}{l}\text { Percurso } 3 \text { - Fig. } 18 \\
\text { (homogeneidade) }\end{array}$ \\
\hline \multicolumn{4}{|c|}{ ARQUITETOS - 38 RESPONDENTES } \\
\hline Muito Satisfatório & $1(2,6 \%)$ & $0(0 \%)$ & $10(26,3 \%)$ \\
\hline Satisfatório & $7(18,4 \%)$ & $10(26,3 \%)$ & $18(47,4 \%)$ \\
\hline Nem Satisfatório, Nem Insatisfatório & $9(23,7 \%)$ & $13(34,2 \%)$ & $9(23,7 \%)$ \\
\hline Insatisfatório & $15(39,5 \%)$ & $12(31,6 \%)$ & $1(2,6 \%)$ \\
\hline Muito Insatisfatório & $6(15,8 \%)$ & $3(7,9 \%)$ & $0(0 \%)$ \\
\hline mvo Kendall & 1,54 & 1,71 & 2,75 \\
\hline mvo K-W & 50,86 & 52,01 & 54,32 \\
\hline \multicolumn{4}{|c|}{ NÃO ARQUITETOS COM FORMAÇÃO UNIVERSITÁRIA - 69 RESPONDENTES } \\
\hline Muito Satisfatório & $2(2,9 \%)$ & $5(7,2 \%)$ & $25(36,2 \%)$ \\
\hline Satisfatório & $21(30,4 \%)$ & $24(34,8 \%)$ & $33(47,8 \%)$ \\
\hline Nem Satisfatório, Nem Insatisfatório & $20(29 \%)$ & $19(27,5 \%)$ & $6(8,7 \%)$ \\
\hline Insatisfatório & $18(26,1 \%)$ & $17(24,6 \%)$ & $5(7,2 \%)$ \\
\hline Muito Insatisfatório & $8(11,6 \%)$ & $4(5,8 \%)$ & $0(0 \%)$ \\
\hline mvo Kendall & 1,55 & 1,80 & 2,64 \\
\hline mvo K-W & 61,99 & 62,67 & 62,16 \\
\hline \multicolumn{4}{|c|}{ RESPONDENTES SEM FORMAÇÃO UNIVERSITÁRIA - 10 RESPONDENTES } \\
\hline Muito Satisfatório & $0(0 \%)$ & $1(10 \%)$ & $3(30 \%)$ \\
\hline Satisfatório & $3(30 \%)$ & $2(20 \%)$ & $4(40 \%)$ \\
\hline Nem Satisfatório, Nem Insatisfatório & $5(50 \%)$ & $4(40 \%)$ & $3(30 \%)$ \\
\hline Insatisfatório & $2(20 \%)$ & $3(30 \%)$ & $0(0 \%)$ \\
\hline mvo Kendall & 1,70 & 1,75 & 2,55 \\
\hline mvo K-W & 69,35 & 60,20 & 55,00 \\
\hline
\end{tabular}

Tabela 2. Níveis de satisfação com a aparência dos percursos - Variedade de pisos ao longo da quadra

Notas: $m v$ Kendall= média dos valores ordinais obtida através do teste Kendall $W$; mvo $K-W=$ média dos valores ordinais obtida através do teste Kruskal-Wallis; a comparação entre os valores de mvo Kendall deve ser feita na horizontal, entre as vistas; a comparação entre os valores mvo $K-W$ deve ser feita na vertical, entre os grupos.

A ordem de preferência dos percursos para os arquitetos revela claramente a preferência pelo percurso homogêneo (percurso 3) e a menor preferência pelo percurso com alta heterogeneidade de pisos (percurso 1), o que confirma suas avaliações individuais dos percursos (Tabelas 2 e 3). A ordem de preferência dos percursos para os não arquitetos com formação universitária corrobora suas avaliações individuais dos 
percursos e mostra a preferência pelo percurso de calçada com pisos homogêneos (percurso 3) e a menor preferência pelo percurso com alta heterogeneidade de pisos (percurso 1) (Tabelas 2 e 3). Embora persista a maior preferência pelo percurso de calçada com pisos homogêneos (percurso 3) por parte daqueles sem formação universitária, o percurso menos preferido é aquele representado pela alta variedade de pisos (percurso 1), e não o percurso 2, avaliado negativamente por este grupo. Contudo, ambos os percursos apresentam claras variações de pisos (Tabelas 2 e 3). Assim, a ordem de preferência dos percursos tende a ser sustentada pelas suas avaliações individuais, existindo uma clara tendência para o percurso com calçada de pisos homogêneos provocar as reações estéticas mais positivas, e uma rejeição para a heterogeneidade de pisos ao longo de uma mesma quadra.

\begin{tabular}{c|c|c|c|c|c|c|c|c|c|c}
\hline \multicolumn{2}{c|}{ Total } & \multicolumn{3}{c|}{ Arquitetos } & \multicolumn{3}{c|}{$\begin{array}{c}\text { Não arquitetos com } \\
\text { formação universitária }\end{array}$} & \multicolumn{3}{c}{$\begin{array}{c}\text { Respondentes sem } \\
\text { formação universitária }\end{array}$} \\
\hline Percurso & Mv K & Percurso & Mv K & MvK-W & Percurso & Mv K & MvK-W & Percurso & Mv K & MvK-W \\
\hline $3(177)$ & 1,53 & $3(52)$ & 1,38 & 54,50 & $3(107)$ & 1,57 & 59,96 & $3(18)$ & 1,75 & 69,45 \\
\hline $2(240)$ & 2,07 & $2(81)$ & 2,12 & 62,68 & $2(140)$ & 2,06 & 57,99 & $2(19)$ & 2,00 & 52,00 \\
\hline $1(278)$ & 2,40 & $1(95)$ & 2,50 & 64,30 & $1(161)$ & 2,37 & 56,96 & $1(22)$ & 2,25 & 52,90 \\
\hline
\end{tabular}

Tabela 3. Ordem de preferência dos percursos quanto à aparência das variedades de pisos.

Notas: Mv K - média dos valores ordinais obtida através do teste Kendall W; Mv K-W - média dos valores ordinais obtida através do teste Kruskal-Wallis; coluna "Percurso" - valor fora dos parênteses = percurso em avaliação [valor entre parênteses = pontuação total recebida, variando da maior (1 ponto) para a menor (3 pontos) preferência por cada respondente].

\begin{tabular}{|c|c|c|c|c|c|c|}
\hline Justificativas & $\begin{array}{l}\text { Arquitetos } \\
38(100 \%)\end{array}$ & $\begin{array}{l}\text { N arq c f uni } \\
69(100 \%)\end{array}$ & $\begin{array}{c}\text { Resp s f uni } \\
10(100 \%)\end{array}$ & $\begin{array}{c}\text { Total } \\
117(100 \%)\end{array}$ & SIG & PHI \\
\hline \multicolumn{7}{|c|}{ JUSTIFICATIVAS PARA OS PERCURSOS MELHOR AVALIADOS } \\
\hline Cor uniforme dos pisos & $23(60,5 \%)$ & $38(55,1 \%)$ & $2(20 \%)$ & $63(53,8 \%)$ & 0,069 & 0,214 \\
\hline $\begin{array}{l}\text { Nenhuma mudança de piso ao } \\
\text { longo da quadra }\end{array}$ & $19(50,0 \%)$ & $26(37,7 \%)$ & $3(30 \%)$ & $48(41,0 \%)$ & 0,352 & 0,134 \\
\hline Pisos do mesmo tamanho & $20(52,6 \%)$ & $25(36,2 \%)$ & $2(20 \%)$ & $47(40,2 \%)$ & 0,101 & 0,198 \\
\hline $\begin{array}{l}\text { Pouca mudança de piso ao longo } \\
\text { da quadra }\end{array}$ & $13(34,2 \%)$ & $28(40,6 \%)$ & $5(50 \%)$ & $46(39,3 \%)$ & 0,625 & 0,090 \\
\hline Cor neutra dos pisos & $16(42,1 \%)$ & $23(33,3 \%)$ & $2(20 \%)$ & $41(35,0 \%)$ & 0,384 & 0,128 \\
\hline $\begin{array}{l}\text { Diferentes composições com o } \\
\text { mesmo piso ao longo da quadra }\end{array}$ & $3(7,9 \%)$ & $7(10,1 \%)$ & $2(20 \%)$ & $12(10,3 \%)$ & 0,532 & 0,104 \\
\hline Variedade de cores dos pisos & $3(7,9 \%)$ & $5(7,2 \%)$ & $2(20 \%)$ & $10(8,5 \%)$ & 0,397 & 0,126 \\
\hline \multicolumn{7}{|c|}{ JUSTIFICATIVAS PARA OS PERCURSOS PIOR AVALIADOS } \\
\hline $\begin{array}{l}\text { Muita mudança de piso ao longo } \\
\text { da quadra }\end{array}$ & $31(81,6 \%)$ & $56(81,2 \%)$ & $8(80 \%)$ & $94(80,3 \%)$ & 0,962 & 0,026 \\
\hline Variedade de tamanhos de pisos & $18(47,4)$ & $36(52,2 \%)$ & $3(30 \%)$ & $57(48,7 \%)$ & 0,415 & 0,123 \\
\hline Variedade de cores dos pisos & $22(57,9 \%)$ & $32(46,4 \%)$ & $1(10 \%)$ & $55(47,0 \%)$ & 0,026 & 0,250 \\
\hline $\begin{array}{l}\text { Diferentes composições com o } \\
\text { mesmo piso ao longo da quadra }\end{array}$ & $14(36,8 \%)$ & $23(33,3 \%)$ & $1(10 \%)$ & $38(32,5 \%)$ & 0,265 & 0,151 \\
\hline
\end{tabular}

As razões mencionadas pelos respondentes para justificar suas preferências evidenciam a importância de calçadas uniformes, com pouca ou nenhuma mudança de piso ao longo de uma mesma quadra, para gerar percepções estéticas mais positivas. Ainda, os arquitetos e não arquitetos tendem a avaliar como positivo pisos do mesmo tamanho, de cores neutras e uniformes (Tabela 4). Por outro lado, o impacto de muita mudança de pisos em uma mesma quadra tem relação com as percepções estéticas menos positivas, para os três grupos. 
Além disso, os arquitetos e não arquitetos com formação universitária indicaram as diferentes composições com o mesmo piso, assim como, a variedade de tamanhos e de cores como justificativas para suas avaliações negativas (Tabela 4).

Ainda, não foram encontradas diferenças estatisticamente significativas (teste Kruskal-Wallis) entre os três grupos com distintos níveis e tipos de formação acadêmica quanto às suas avaliações estéticas e preferências pelas vistas, confirmando que tais avaliações e preferências são similares e, logo, que não foram afetadas significativamente pelo nível e tipo de formação acadêmica de cada grupo.

\section{Considerações finais}

Os principais resultados, com relação à preferência dos pisos de calçadas, sustentam a hipótese (a), quanto mais neutro e com menos detalhes for o piso, maior o impacto estético positivo, independentemente do nível e tipo de formação do observador. Assim, estes resultados indicam a necessidade de uma revisão dos guias, normas e legislações brasileiras (p. ex., Decreto N 17.302, 2011; Decreto № 45.904, 2005; WRI Brasil, 2017), que possibilitam uma grande variedade de tipos de pisos, sem orientações detalhadas quanto à escolha adequada e harmonização com o entorno ou adjacências ao invés de indicarem pisos de desenhos mais simples, de tamanhos regulares e cores discretas. Por outro lado, o resultado vai ao encontro de diretrizes do novo guia da cidade de Florianópolis (SMDU e IPUF, 2018) que aconselha evitar a utilização de padronagem na pavimentação, por exemplo, com desenhos ou cores que remetam à impressão de tridimensionalidade, em razão da sensação de insegurança que esse tipo de estampas nos pisos podem causar no usuário.

Os resultados das avaliações da aparência dos diferentes níveis de variação de pisos, ao longo de uma mesma quadra, revelaram que percursos com distintos níveis de heterogeneidade são avaliados diferentemente, indicando qualidades estéticas variadas. As explicações estão no impacto estético positivo pela uniformidade de pisos ao longo de uma mesma quadra, enquanto que a mudança de pisos está ligada às avaliações negativas das aparências das calçadas, assim como a escolha pelo percurso menos preferido. Isso demonstra uma clara preferência por parte dos três grupos de respondentes, pelo percurso com calçadas de pisos homogêneos e uma rejeição pelos percursos com calçadas de pisos heterogêneos. Esses resultados vão ao encontro de recomendações de cidades como Londres (Transport for London, 2017), onde um dos critérios para a escolha dos pisos das calçadas é sua harmonização com o conjunto de elementos que fazem parte do espaço urbano e como Florianópolis (SMDU e IPUF, 2018), que desde 2018 recomenda que antes de executar a calçada o proprietário deve verificar qual o tipo de piso mais utilizado na maior parte da quadra. Ademais, os resultados sustentam a segunda hipótese (b) apresentada, confirmando que quanto maior a variação dos pisos das calçadas ao longo de uma mesma quadra, com relação a cores, texturas, formato, tamanho e disposição, maior o impacto estético negativo, independentemente do nível e tipo de formação do observador. Contudo, mesmo recomendando a continuidade da padronagem da calçada ao longo da quadra, vários guias (p.ex., GDCI e NACTO, 2016; WRI Brasil, 2017) indicam a diferenciação de faixas nas calçadas (faixa de serviço, faixa livre e faixa de acesso), com diferentes cores e/ou texturas de pisos.

Desta maneira as avaliações estéticas das calçadas evidenciam a clara preferência pelos pisos uniformes, portanto, sugerindo que as pessoas prefeririam caminhar em calçadas com revestimentos homogêneos, de tamanhos constantes e cores uniformes, o que por sua vez está em sintonia com as orientações do guia de Londres, de que a calçada no espaço aberto público deve torna-se um "carpete neutro", sem competir com as edificações adjacentes (Transport for London, 2017). Os efeitos estéticos positivos da presença de ordem e os efeitos negativos da existência de desordem também tem sido evidenciados em estudos que tratam da estética urbana, onde cenas com ordem tendem, claramente, a ser bem melhor avaliadas do que aquelas com desordem (p.ex., Reis; Biavatti e Pereira, 2011). Por outro lado, ainda que existam muitas publicações que tratem da qualidade das calçadas, são escassos os estudos sobre o impacto estético da variação e a 
preferência da pavimentação das calçadas, na percepção de diferentes grupos de usuários (p. ex., Andrade et. al, 2017; Mintz, 2015). Assim, os resultados deste estudo possibilitam uma melhor compreensão acerca da estética de calçadas com diferentes tipos e variações de pisos, contribuindo também para um melhor entendimento da experiência estética nos espaços urbanos. Contudo é importante aprofundar o conhecimento acerca do efeito estético das calçadas incluindo elementos tais como arborização e presença de mobiliário urbano.

\section{BIBLIOGRAFIA}

ABNT NBR 1338 (1990). Execução e utilização de passeios públicos. Associação de Normas Brasileiras, Rio de Janeiro, Brasil, dezembro de 1990.

ABNT NBR 9050 (2015). Acessibilidade a edificações, mobiliário, espaços e equipamentos urbanos. Associação de Normas Brasileiras, Rio de Janeiro, Brasil, 11 de setembro de 2015.

ANDRADE ET. AL. (2017). Índice de caminhabilidade: avaliação na escala bairro. Em: ANDRADE, V. e LINKE, C (Org.). Cidade de pedestres: a caminhabilidade no Brasil e no mundo (146-159). Rio de Janeiro: Babilonia Cultural Editorial.

Decreto $N^{\circ} 45.904$ (2005). Regulamenta o artigo $6^{\circ}$ da Lei $n^{0} 13.885$, de 25 de agosto de 2004, no que se refere à padronização dos passeios públicos do Município de São Paulo. Diário Oficial, São Paulo, Brasil, 19 de maio de 2005.

Decreto $N^{\circ} 17.302$ (2011). Dispõe sobre a pavimentação de passeios públicos. Diário Oficial, Porto Alegre, Brasil, 15 de setembro de 2011.

GDCI e NACTO. (2016). Global Street Design Guide. New York: Island Press, USA.

Government of The District of Columbia. (2011). Public Realm Design Manual. Office of Planning: Washington.

HANDCOCK, M. S. E GILE, K. J. (2011). On the Concept of Snowball Sampling. Sociological Methodology ASA, v. 41, n. 1, p.367-371.

LAY, M. C. D. E REIS, A. T. DA L. (2005). Análise quantitativa na área de estudos ambiente-comportamento. Ambiente Construido (Porto Alegre), v. 5, n. 2, 21-36.

Lei Complementar № 482 (2014). Institui o Plano Diretor de Urbanismo do município de Florianópolis que dispõe sobre a política de desenvolvimento urbano, o plano de uso e ocupação, os instrumentos urbanísticos e o sistema de gestão. Diário Oficial, Florianópolis, Brasil, 17 de janeiro de 2014.

Lei N 1.350 (1988). Autoriza o Poder Executivo a tornar obrigatórias a limpeza, conservação ou construção de calçadas diante de imóveis residenciais e/ou comerciais e terrenos baldios, no Município do Rio de Janeiro, na forma que menciona, Diário Oficial, Rio de Janeiro, 26 de outubro de 1988.

Lei № 3.144 (2005). Padroniza as calçadas no município de Foz do Iguaçu e dá outras providências. Diário Oficial, Foz do Iguaçu, Brasil, 14 de dezembro de 2005.

LYNCH, K. (2008). La imagen de la ciudad. $8^{\circ}$ ed., Traduzido por Enrique Luis Revol, The Massachusetts Institute of Technology Press, Barcelona: Editorial Gustavo Gili.

Melbourne City Council. (2013). Design and Construction Standards for Public Infrastructure Works in the Docklands Area. Melbourne. 
MINTZ, N. (2015). Pela força de 10. Em: KASRSSENBERG, H.; LAVEN, J.; GLASER, M. e HOFF, M. (Ed.). A cidade ao nível dos olhos - Lições para os plinths. Traduzido por Paulo Horn Regal e Renee Nycolaas. (81-85) Porto Alegre: EdiPUCRS.

REIS, A. T. DA L.; BIAVATTI, C. D. E PEREIRA, M. L. (2011). Estética urbana: uma análise através das ideias de ordem, estímulo visual, valor histórico e familiaridade. Ambiente Construído (Porto Alegre), v. 11, n. 4, 185204.

SMDU e IPUF. (2018). Calçada certa - manual de projeto e execução. Versão 01, Cadernos de Planejamento e Projetos Urbanos de Florianópolis, Prefeitura de Florianópolis/Rede de Espaços Públicos, Florianópolis.

Transport for London. (2017). Streetscape Guidance. 3a. ed. London, UK: Transport for London - Every Journey Matters.

VAN CAUWENBERG, J. et al. (2012). Environmental factors influencing older adults' walking for transportation: a study using walk-along interviews. International Journal of Behavioral Nutrition and Physical Activity, v. 9, p.111.

WRI Brasil (2017). 8 princípios da calçada - construindo cidades mais ativas. 1a. ed. Brasil: Creative Commons. 